\title{
Há algo a temer na "Teoria da Restauração" de Brandi? O mito paralisante do medo
}

\section{Is there anything to be afraid of in Brandi's "Teoria del restauro"? The paralyzing myth of fear}

\author{
VIEIRA-DE-ARAÚJO, Natália Miranda ${ }^{1}$
LIRA, Flaviana ${ }^{2}$ \\ VIEIRA-DE-ARAÚJO, Natália Miranda ${ }^{1}$
LIRA, Flaviana ${ }^{2}$
}

1Programa de Pós-graduação em Desenvolvimento Urbano, Universidade Federal de Pernambuco, Recife, Brasil e Programa de Pós-graduação em Arquitetura e Urbanismo, Universidade Federal do Rio Grande do Norte, Natal, Brasil. vieira.m.natalia@gmail.com ORCID 0000-0002-4756-9822

2 Programa de Pós-graduação em Arquitetura e Urbanismo, Faculdade de Arquitetura e Urbanismo, Universidade de Brasília, Brasília, Brasil. flavianalira@hotmail.com ORCID 0000-0003-2259-4885

\begin{abstract}
Resumo
Nos últimos anos, testemunha-se o surgimento de publicações na área de conservação e restauração, defendendo a ideia de que a "Teoria da Restauração" de Cesare Brandi se tornou antiquada e até mesmo impossível de compreender, devido à identificação de contradições e à leitura difícil decorrente de uma pretensa erudição de sua escrita na língua italiana. Este artigo tem como objetivo discutir alguns dos pontos apresentados pelo autor espanhol Salvador Muñoz Viñas como contradições encontradas na teoria de Brandi. Eles são realmente contradições? Interpretações reducionistas acabam levando a um debate polarizado, que tende a cair na crítica pela crítica. Este artigo defende a necessidade de superar essa dicotomia improdutiva entre "brandianos por excelência" e "pósmodernistas" na conservação do patrimônio cultural. Para o desenvolvimento desse argumento, será discutido o conceito de restauração, os temas de integridade, autenticidade e o conceito brandiano de unidade potencial da obra de arte.
\end{abstract}

Palavras-Chave: restauração; Cesare Brandi; Muñoz Viñas; unidade potencial; integridade; autenticidade.

\begin{abstract}
In the last few years we have witnessed the upsurge of publications in the area of conservation and restoration defending the idea that Cesare Brandi's "Teoria del restauro" has become antiquated and is even impossible to comprehend, due to the identification of inherent contradictions and the difficult reading of its complex form of Italian language. This article aims to discuss some of the points presented by the Spanish author Salvador Muñoz Viñas as contradictions found in Brandi's theory. Are they really contradictions? Reductionist interpretations end up leading to an polarized debate, that tends to fall into criticism for the sake of criticism. Here we would like to emphasize the need to get over this unproductive dichotomy between "brandians par excellence" and "postmodernists" of conservation. To the development of our argument, we will discuss the concept of restoration, the themes of integrity, authenticity and the brandian concept of potential unity.
\end{abstract}

Key-Words: restoration; Cesare Brandi; Muñoz Viñas; potential unit; integrity; authenticity. 


\section{Por um campo disciplinar em contínua construção}

A preservação do patrimônio cultural envolve questões de grande complexidade que pressupõem a necessidade de seu enfrentamento a partir de uma abordagem cada vez mais abrangente, interdisciplinar e inclusiva do ponto de vista social.

Lira (2018), ao tratar do assunto, dispõe que o Instituto do Patrimônio Histórico e Artístico Nacional (IPHAN), buscando atualizar seus instrumentos de tutela e salvaguarda, de modo a envolver as comunidades nas ações de conservação do patrimônio nacional, divulgou, no dia 17 de setembro de 2018, em seu sítio eletrônico, a informação de que será criado instrumento de proteção novo, "Lugares de memória". De acordo com a notícia, "Por meio desse reconhecimento, ainda que um bem cultural tenha perdido sua integridade e autenticidade, em consequência da ação humana ou do tempo, o Iphan poderá reconhecer a importância de seus valores simbólicos."1

É particularmente significativo esse movimento de ampliação e revisão de instrumentos por parte do IPHAN, uma instituição que até os anos 2000, quando foi criado o Programa Nacional do Patrimônio Imaterial, tinha suas práticas de salvaguardas respaldadas primordialmente no instrumento do tombamento do patrimônio material (LIRA, 2018).

Essa abertura e democratização do campo, todavia, não pressupõe a superação dos princípios básicos construídos ao longo de mais de um século de reflexão teórica do campo da restauração. Toma-se aqui como pressuposto que tais princípios permanecem fundamentais para a atuação preservacionista em áreas de interesse histórico e cultural, ainda que as ações de gestão e conservação sobre ele nem sempre sejam conduzidas com o rigor metodológico necessário.

Nesse sentido, entende-se que não se pode tomar decisões que visam enfrentar o desafio de buscar a conciliação entre as necessidades de adaptação aos usos contemporâneos e a preservação dos valores patrimoniais identificados em um bem ou em um sítio, sem se conhecer todo o instrumental teórico-metodológico que o campo da preservação construiu, especialmente ao longo dos dois últimos séculos (VIEIRA-DE-ARAÚJO, 2014).

Por outro lado, entender este tipo de projeto/ação como o espaço para a aplicação de um receituário pré-estabelecido ou de uma linha dogmática a ser seguida não é a solução. Este tipo de postura também tem gerado distorções no entendimento das ações sobre a preexistência de valor patrimonial, ${ }^{2}$ levando à falsa compreensão de que necessitamos de uma "nova" teoria do restauro. Permanecemos convencidas de que o conhecimento da teoria do restauro não é garantia de respeito à cidade e ao patrimônio cultural, mas, sem dúvida, constitui-se em um importante passo, por meio do qual a formação de um juízo crítico (BRANDI, 2004), fundamentado na significância cultural do bem, pode auxiliar de forma decisiva na tomada de decisões.

\footnotetext{
${ }_{1}^{1}$ Disponível em: http://portal.iphan.gov.br/noticias/detalhes/4829/politica-de-patrimonio-cultural-material-fortaleceacoes-de-preservacao-no-brasil. Acessado em 29 set. 2018.

2 Para o conceito de "valor patrimonial" utilizaremos a conceituação de Tiesdell,Oc,Heath (1996), que, ao classificar os diferentes valores envolvidos na revitalização de áreas históricas, identificam o "valor de continuidade da memória cultural" que os autores colocam como sinônimo de "valor de patrimônio" ou valor patrimonial. Para estes autores este valor corresponde: "Evidências visíveis do passado podem contribuir pedagogicamente e educacionalmente para a identidade cultural e a memória de determinado povo ou lugar, localizando a sociedade contemporânea em relação à tradição anterior e dando sentido ao presente através da interpretação do passado" (TIESDELL,OC,HEATH, 1996, p. 15,16 - tradução nossa). Compreendemos, então, que o valor patrimonial é o aspecto material considerado representativo de determinado valor cultural ("evidências visíveis do passado"). Enquanto o valor cultural tem uma significação e abrangência muito mais ampla, o valor patrimonial é a representação material de determinada identidade cultural, presente, por exemplo, no patrimônio edificado (Sobre essa discussão de valores ver também VIEIRA, 2008).
} 
É preciso lembrar ainda que, tão importante quanto o conhecimento teórico-metodológico, é o (re)conhecimento do sítio onde se insere o bem que se deseja preservar (VIEIRA-DE-ARAÚJO, 2017), bem como, a participação de todos os envolvidos.

A partir destas premissas, o presente artigo pretender analisar de forma detida as reflexões desenvolvidas pelo espanhol Salvador Muñoz Viñas, professor do Departamento de Conservação da Universidad Politécnica de Valencia, em especial, a publicação de 2003 intitulada "Teoria Contemporanea de la Restauración" (MUÑOZ VIÑAS, 2003).

Apesar do título um tanto quanto pretencioso, "Teoria Contemporanea de la Restauración" (MUÑOZ VIÑAS, 2003), Muñoz Viñas inicia seu livro ressaltando que a "teoria contemporânea" por ele designada já existe, porém, "em um estado difuso" e que seu objetivo é fornecer um "fio condutor que confere forma a esse amalgama de ideias diversas" que compõem a teoria contemporânea da restauração (MUÑOZ VIÑAS, 2003, p.14). O autor ressalta que, se por um lado, temos as por ele chamadas de "teorias clássicas" e seus textos canônicos sendo editados e reeditados nos mais variados meios, por outro, a "teoria contemporânea" aparece "muitas vezes de forma secundária ou implícita, em artigos, conferências, na internet” (MUÑOZ VIÑAS, 2003, p. 13, tradução nossa).

Muñoz Viñas identifica esse estado "fragmentário" como uma das principais desvantagens dessa teoria contemporânea e alerta ainda que esta exige "esforço intelectual de adaptação aqueles que já conheciam as teorias clássicas" (MUÑOZ VIÑAS, 2003, p. 14, tradução nossa). Como vantagens, o autor elenca os seguintes adjetivos e descrições: é "nova", é "desmistificadora", "emprega instrumentos conceituais mais flexíveis" (MUÑOZ VIÑAS, 2003, p. 14, tradução nossa).

Será mesmo que podemos fazer esta separação entre "teorias clássicas" e "teoria contemporânea"? Ou não estaremos em um contínuo debate teórico, de um campo de reflexão consolidado, e que deve ser entendido como um conjunto fluído, em permanente atualização, no qual não cabe colocar uma linha divisória entre "antes e depois", "ontem e hoje" ou "clássico e contemporâneo" (para usar os termos do autor), como nos quer convencer o teórico espanhol?

As reflexões apresentadas neste artigo apontam para uma resposta afirmativa para a segunda pergunta. O próprio Muñoz Viñas dá pistas nesse sentido ao reconhecer que "algumas das ideias que embasam a teoria contemporânea da restauração já foram expressas em princípios do século XX" (MUÑOZ VIÑAS, 2003, p.14), referindo-se especificamente à contribuição do austríaco Aloïs Riegl com seu célebre "O culto moderno dos monumentos: sua essência e gênese" (RIEGL, 2006), publicado originalmente em 1903.

É impossível não reconhecer muitas das questões e abordagens desenvolvidas por Riegl na reflexão e defesa da construção de um "juízo crítico" desenvolvido por Brandi (2004) nos anos de 1960 e vários outros representantes importantes do chamado "restauro crítico", como Paul Philippot, Roberto Pane e Giovanni Carbonara. A utilização de instrumentos conceituais mais flexíveis que Muñoz Viñas identifica como qualidade e característica dessa suposta "teoria contemporânea", aqui é tomada como o desenvolvimento e amadurecimento de conceitos já postos pela teoria do restauro.

Assim, este artigo empreende a discussão proposta a partir da atenção especial para com os conceitos de restauração, obra de arte, bem cultural, Unidade Potencial, autenticidade e integridade. Com isso, objetiva-se analisar em que medida tais conceitos e entendimentos elaborados pela via crítica do restauro, em especial a partir das reflexões de Cesare Brandi (2004), foram superados na teoria contemporânea proposta por Muñoz Viñas (2003) ou se, ao contrário disto, não houve rupturas, mas, sim, continuidades com a abordagem metodológica brandiana. 


\section{Colocando os pingos nos "is": o conceito de "Restauração"}

Antes de qualquer coisa, é preciso delimitar o entendimento do termo "restauração" aqui adotado. Essa questão, que pode parecer semanticamente de pouca importância, é, na verdade, central à discussão uma vez que, dependendo do país onde o debate acontece, os sentidos podem ser bastante distintos.

No primeiro capítulo do seu livro "Teoria Contemporanea de la Restauración", chamado de "Identidade e Fundamentos da Restauração", Muñoz Viñas (2003) se concentra na apresentação e discussão de conceitos por ele entendidos como centrais à reflexão. $O$ autor desenvolve especificamente qual o seu entendimento para o conceito de "restauração":

Em espanhol, e em outros idiomas latinos, o termo restauração se emprega indistintamente para descrever tanto o conjunto de atividades próprias do restaurador (o que às vezes se tem denominado conservação e restauração - este é o sentido em que se emprega o título desse livro) como a restauração propriamente dita, ou seja, como uma atividade própria do restaurador mas oposta a outras como a conservação ou a conservação preventiva (MUÑOZ VIÑAS, 2003, p. 17, tradução nossa).

A partir dessa explicação, o autor estabelece uma convenção para a escrita de seu livro: quando utiliza a palavra Restauração com "R" maiúsculo, refere-se ao sentido amplo (conjunto de atividades próprias do restaurador: restauração e conservação) e quando utiliza a palavra restauração com "r" minúsculo, refere-se ao sentido específico (ações de estrita restauração, que não incluem ações de conservação). Para a Restauração em sentido amplo, ele identifica três grandes categorias assim descritas:

1. Preservação ou conservação ambiental (indireta ou periférica), é a atividade que consiste em adequar as condições ambientais em que se insere um bem para que este mantenha seu estado presente (MUÑOZ VIÑAS, 2003, p. 23- 24);

2. Conservação, ou conservação direta, é a atividade que consiste em preparar um bem determinado para que ele possa experimentar a menor quantidade possível de alterações, intervindo diretamente sobre ele, estando incluída alterações ou melhoras em suas características não perceptíveis -não perceptíveis para um espectador médio, nas condições habituais de observação do bem. A conservação direta também pode alterar feições perceptíveis, mas só por imperativos técnicos (MUÑOZ VIÑAS, 2003, p. 23- 24);

3. Restauração é a atividade que aspira a devolver a um estado anterior as feições perceptíveis de um dado bem - perceptíveis para um espectador médio, nas condições normais de observação (MUÑOZ VIÑAS, 2003, p. 23- 24).

A pesquisadora brasileira Beatriz Mugayar Kühl, em seu livro "Preservação do Patrimônio Arquitetônico da Industrialização: Problemas Teóricos de Restauro" (KÜHL, 2008), apresenta um panorama da forma como são entendidos os conceitos de preservação, conservação e restauro em vários contextos nacionais diferentes. Kühl ressalta que, no Brasil, seguindo a tradição francesa, é a palavra "preservação" normalmente utilizada de forma a abranger as diferentes ações que se podem realizar para com o patrimônio cultural: desde ações de gestão, inventários, registros, instrumentos de tutela, educação patrimonial, até os variados tipos de intervenção sobre os bens que podem assumir formas de manutenção, conservação e restauração (KÜHL, 2008, p. 59). Então, "preservação", no Brasil e na França, seria o mais próximo da "Restauração" (com R maiúsculo) de Muñoz Viñas, apesar de aquela ser ainda mais abrangente que esta, incluindo também as ações ligadas à gestão. 
Já no ambiente italiano, a autora informa que se usam os termos "conservazione e tutela" para este sentido lato, semelhante ao uso brasileiro da palavra "preservação". "Conservazione" também é utilizado para identificar um dos graus de atuação sobre o patrimônio material, ação distinta da manutenção e do restauro (KÜHL, 2008, p. 73). Kühl (2008, p.73) destaca ainda que na Inglaterra o termo "restoration" "permanece com conotação extremamente negativa pela repercussão do pensamento ruskiniano, utilizando-se "conservation" tanto para bens móveis quanto imóveis". Já nos Estados Unidos, segundo a autora, a palavra "conservation" utiliza-se mais para bens móveis e "preservation" para bens imóveis.

É significativo desta mudança de entendimento dos termos de país para país, a tradução realizada para o inglês do livro de Muñoz Viñas, cujo título passa a se chamar "Contemporary Conservation Theory", sendo, então, substituído o termo espanhol "Restauración" pelo termo "Conservation". Sobre esta confusão no emprego destes termos, Kühl (2018, p. 73, grifo nosso) conclui que:

Essa falta de uniformidade no emprego dos termos entre as várias línguas e, muitas vezes, na mesma língua - uma notável exceção é o ambiente italiano, em que esforços de conceituação se destacam, havendo de fato uma relação entre a palavra e o significado que ela adquiriu para o campo disciplinar -, dependendo do ambiente que se trabalha, comparece até mesmo em documentos internacionais, bastando se verificar, no âmbito do ICOMOS, as diferentes versões da Carta de Veneza nas várias línguas, e a contradição entre os termos ali presentes e aqueles definidos na Carta da Burra, do comitê nacional do ICOMOS australiano.

O conceito de "restauração" no ambiente italiano tem, então, uma longa reflexão teórica e é utilizado no sentido de uma atuação específica sobre o patrimônio. Apesar de existirem diferentes correntes de restauro na Itália contemporânea ${ }^{3}$, quando se fala em "restauração" nesse país, não está se falando do sentido amplo entendido no ambiente espanhol e convencionado por Muñoz Viñas como Restauração com "R" maiúsculo. Na sessão seguinte, será discutida as consequências da falta de uniformidade dos termos para a crítica que Muñoz Viñas desenvolverá sobre a postura do italiano Cesare Brandi.

\section{Do conceito de obra de arte de Brandi ao entendimento de bem cultural}

Após entender o conceito de restauração, Muñoz Viñas (2003, p. 24-36) dá continuidade a sua "Teoria Contemporanea de la Restauración" desenvolvendo uma reflexão sobre o que são exatamente "os objetos de Restauração". Afinal, de que se ocupa a "Restauração"? O autor inicia questionando o critério da "antiguidade" por ser "ambíguo e pouco útil para caracterizar os objetos de Restauração" e continua sua exposição também rechaçando a ideia de "Restauração" de obras de arte. É importante ressaltar que aqui o autor sempre se refere à Restauração com "R" maiúsculo, ou seja, está falando de seu sentido ampliado.

Muitos teóricos, geralmente procedentes do campo da história da arte, como Brandi (1999), Walden (1985) ou Beck (1994), assumem tacitamente que a Restauração se ocupa exclusivamente de obras de arte (MUÑOZ VIÑAS, 2003, p. 25, tradução nossa).

\footnotetext{
${ }^{3}$ No contexto italiano contemporâneo, existem três posturas principais de restauração identificadas por Giovanni Carbonara (1997), são elas: a "crítico-conservativa e criativa", fortemente baseada na restauração crítica e na teoria de Brandi; a "pura conservação" ou "conservação integral", na qual a instância histórica é preferencial; e a "manutenção-repristinação", por meio da qual técnicas e formas do passado são trazidas de volta para superar o "estado fragmentário" do bem.
} 
O autor continua ressaltando que o defensor mais conhecido dessa abordagem é Cesare Brandi ("que alcançou grande celebridade") e segue citando o conceito brandiano de restauração. A crítica mais recorrente à abordagem brandiana está relacionada ao fato de que o autor coloca a restauração como uma atividade exclusivamente voltada para as obras de arte. Muñoz Viñas (2003) contesta sua abordagem por entendê-la como reducionista.

Segundo Muñoz Viñas, a linguagem "critica e ambígua" da "Teoria do Restauro" de Cesare Brandi tem "fomentado o desenvolvimento de múltiplas interpretações de natureza mais ou menos criativa". Chama a atenção, entretanto, que a crítica deste autor se fundamenta em seu conceito ampliado para o termo "Restauração", enquanto Brandi, por sua vez, está tratando da ação de restauração em seu sentido mais específico. Assim, a crítica se mostra absolutamente frágil e deslocada.

Muñoz Viñas segue ainda, a partir dessa interpretação deslocada conceitualmente, defendendo a limitação do enfoque voltado para as obras de arte a partir, especialmente, de dois argumentos fundamentais: que a definição do que é arte pode se converter em algo "insuportavelmente complexo" e que hoje há muitos objetos que podem ser passíveis de restauração, embora muitos deles não sejam obras de arte, como maquinário industrial antigo, campos de concentração, mísseis, entre outros. ${ }^{4}$

O autor cita o exemplo de um avião utilizado durante a II Guerra Mundial, o Mustang P51. Depois do fim da guerra, muitos desses aviões foram adquiridos por particulares e, depois de um período de esquecimento, voltaram a ser restaurados. Segundo o autor, essas restaurações foram realizadas do mesmo modo que se faziam os reparos durante a guerra. "O que demonstra esta paródia do Mustang é que um mesmo trabalho realizado sobre um mesmo objeto pode, algumas vezes, ser Restauração e em outras não: para uma atividade ser ou não considerada não estão em questão somente as operações técnicas realizadas, mas também o objeto sobre o qual ela se realiza" (Munõz Viñas, 2003, p. 38, tradução nossa).

Muñoz Viñas conclui que "Definitivamente, a Restauração se ocupa de muitas coisas e restringi-la às obras de arte é uma simplificação excessiva". Além da confusão entre "Restauração" e "restauração" anteriormente comentada, o autor não faz nenhuma referência ao desenvolvimento da corrente críticoconservativa na atualidade e os vários autores que atualizam a contribuição brandiana ampliando o conceito de obra de arte para o conceito de "bem cultural". Apesar de, em seguida, discutir o termo "bem cultural", não faz nenhuma referência a sua utilização pelos adeptos da vertente críticoconservativa.

Levando em consideração o que hoje em dia pode ser considerado patrimônio cultural, é consenso que não se pode entender apenas as obras de arte como objetos de conservação. Essa ampliação, no entanto, não invalida os princípios subjacentes à prática conservacionista, especialmente os propostos pela teoria brandiana crítica (KÜHL, 2007; CARBONARA, 2006; VIEIRA, 2004). Vários dos conceitos introduzidos por Brandi permanecem como importantes ferramentas práticas para a ação intervencionista na dimensão material de edifícios com reconhecido valor patrimonial. O conceito de "Unidade Potencial", por exemplo, fornece uma base pertinente para um trabalho de conservação que visa preservar a autenticidade e a integridade dos bens culturais. Entendendo autenticidade e integridade aqui a partir do seu amadurecimento recente, que incorpora diferentes aspectos que vão além do material, conforme desenvolveremos mais adiante.

\footnotetext{
${ }^{4}$ Para levantar esses argumentos, o autor cita um artigo de Alfonso Jiménez (1998) intitulado "Enmiendas parciales a la teoria del restauro".
} 


\section{O conceito de Unidade Potencial: muito além de uma "visão estética"}

Em seu ímpeto de relativizar a importância ou a contemporaneidade da teoria brandiana, Muñoz Viñas (2003: 23, 24) destaca a coexistência, no final do século XX, do que ele chama de "visão estética" de Brandi com a importante contribuição da "nova conservação científica", caracterizada mais como "uma atitude em relação às técnicas de conservação do que uma teoria da conservação como tal". Nesta "nova conservação científica", as "ciências exatas", como a Física e a Química, têm um papel central. Aqui, destacamos o que consideramos outra interpretação enganosa, uma vez que associa a teoria brandiana apenas ao valor estético, quando, na verdade, esse autor busca claramente um equilíbrio entre a "instância estética" e a "instância histórica".

Em seu $2^{\circ}$ Axioma, no qual Brandi trata da noção de unidade potencial da obra de arte, é disposto que:

[...] a restauração deve visar ao restabelecimento da unidade potencial da obra de arte, desde que isso seja possível, sem cometer um falso artístico ou um falso histórico, e sem cancelar nenhum traço da passagem da obra de arte no tempo (BRANDI, 2004, p.33).

O texto do axioma é claro e não abre espaço para questionamentos: o pensamento brandiano defende que na restauração são as instâncias históricas e estéticas a definir como e o que deve ser restabelecido na unidade formal da obra.

Se a apreensão estética da obra de arte for prejudica, o restauro tem que, sempre que possível, reestabelecer sua unidade potencial. Tome-se o exemplo hipotético de uma igreja que teve a voluta de um dos lados danificada e, por ser simétrica a do lado oposto, era possível a sua reconstrução. Nesse caso a restauração poderia restituir a voluta perdida, no entanto, seguindo os princípios estabelecidos por Brandi, seria imprescindível deixar claro que se tratava de uma reconstrução, de modo a ser claramente percebida em intervenções futuras. Para Brandi, quando não há indícios suficientes do estado original de uma obra, a reconstrução não deve ser realizada, pois há o risco de se criar falsos histórico e artístico. Assim, o que Brandi defende é um profundo conhecimento da obra antes de nela intervir, pois cada situação deve ter uma solução individualizada.

O conceito de unidade potencial, de acordo com Loretto (2016), foi proposto na teoria de Brandi "para controlar a recomposição material de uma obra de arte danificada". É inegavelmente um conceito com uma dupla carga filosófica e operacional (LIRA, 2017) e que nos parece estar intimamente relacionado ao conceito de integridade, um dos crivos exigidos pela UNESCO nos processos de avaliação de bens à Lista do Patrimônio da Humanidade.

Silva (2012) ressalta, a partir da leitura dos documentos da UNESCO, que a integridade está relacionada à completude, ao caráter intacto, à continuidade do contexto. Contemporaneamente, a integridade é entendida como a capacidade do bem de transmitir sua significância cultural. Importa salientar que não diz respeito a uma integridade estacionada no momento de concepção do bem, mas leva em conta suas transformações na história. Está relacionada à manutenção no tempo dos elementos físicos e dinâmicas necessários para se contar a história do bem (LIRA, 2017). Restaurar significa recuperar a integridade perdida, dando ao objeto uma nova unidade potencial (LIRA, 2017).

Também neste aspecto a teoria brandiana revela-se absolutamente atual. A ideia de uma integridade dinâmica, não estacionária no momento da criação, nos obriga a olhar duplamente o bem a ser objeto de intervenção: seu processo de transformação no tempo e as marcas deixadas por tais transformações em suas matéria e imagem. É um entendimento absolutamente convergente ao que Brandi coloca quando afirma que o ato da restauração impõe: 
[...] a instância histórica e a instância estética, que deverão, na recíproca contemporização, nortear aquilo que pode ser o restabelecimento da unidade potencial da obra de arte, sem que venha a constituir um falso histórico ou a perpetrar uma ofensa estética (BRANDI, 2004, p.47).

Portanto, a linha seguida por Brandi, baseada numa "abordagem fenomenológica da arte como elemento que se moderniza diante da consciência individualizada" (LORETTO, 2016), está em perfeito alinhamento com o entendimento de Muñoz Viñas (2003, p. 40) que defende ser a restauração definida "em função de seus objetos" e o que "caracteriza esses objetos são questões subjetivas, estabelecidas pelas pessoas e não inerentes aos objetos". São os valores atribuídos ao objeto que o tornam digno ou indigno de restauração. Em correspondência com essa abordagem, Brandi deixa claro, no final de sua apresentação de "Teoria da Restauração", que não existe restauração absoluta, posto ser esta um ato de cultura.

\section{Um bilhete falso é um autêntico bilhete falso: a autenticidade em Muñoz Viñas}

Dentre os temas discutidos por Munõz Viñas, inclui-se o da autenticidade, e sua abordagem é inovadora:

[...] a ideia de que os objetos podem existir em um estado falso não é correta. Todos os estados por que passou o objeto desde sua criação são testemunhos confiáveis e verdadeiros de sua história [..]. Não há razões objetivas que justifiquem essa suposição [que um estado é mais autêntico que outro]; apelações para conceitos como 'a qualidade artística' ou 'a importância histórica' não podem ser consideradas propriamente objetivas, porque não descrevem características inerentes ao objeto, mas sim, interpretações desenvolvidas pelos sujeitos observadores: constituem critérios subjetivos, ou se se quer dizer, intersubjetivos [...] porque são acordos entre sujeitos (MUÑOZ VIÑAS, 2003, p. 92, itálico do autor, tradução nossa).

Para Muñoz Viñas (2003), a autenticidade está na mente do ser humano, não sendo uma condição inerente aos objetos. Assim, segundo o autor, pode-se discutir a autoria de um objeto, ou sua história, mas não se pode discutir o fato de que esse objeto é autêntico ou real:

[...] Não é a investigação histórica o que se discute aqui, mas sim a existência de objetos em estado de falsidade e, portanto, a validez desse critério para legitimar objetivamente sua modificação. Ainda que uma pintura seja um falso Rembrandt, segue sendo uma autêntica pintura. Se se fala em recuperar o autêntico Rembrandt sob uma tela repintada, também se fala implicitamente em eliminar as autênticas repinturas que cobrem a pintura de Rembrandt, ainda que ambas as pinturas sejam igualmente autênticas; a autenticidade de uma e outra não é um critério objetivo que permita a eliminação de nenhuma delas. $O$ que na realidade legitima essa eliminação é que o valor simbólico (o artístico ou o cultural) resultante da operação é superior ao inicial - ou que alguns sujeitos concedem maior valor historiográfico a um documento sobre a arte de Rembrandt que a outro sobre a arte, ao gosto e às técnicas pictóricas do século XIX (MUÑOZ VIÑAS, 2003, p. 95, tradução nossa).

Muñoz Viñas (2003) que dispôs que o único conceito de verdade, que pode ser considerado real e incontestavelmente verdadeiro, é o estado presente, pois qualquer "[...] outra definição do estado autêntico, ou melhor, do estado historicamente autêntico de um objeto, coincidirá apenas com o que 
uma ou várias pessoas opinem ou imaginem que deveria ser seu estado real, seu estado autêntico [...]"(MUÑOZ VIÑAS, 2003, p. 88, tradução nossa).

Desses entendimentos decorre, portanto, que a verificação da autenticidade não é o resultado direto de uma análise objetiva da matéria do artefato, mas é fruto da percepção que a mente humana tem sobre ele. Aqui, mais uma vez, identificamos uma clara linha de continuidade com o que Brandi dispunha ao afirmar que cada vez que a obra de arte é vista e é apreendida pela mente humana um novo ciclo de apreensão é criado. De acordo com sua teoria, "[...] o único momento legítimo que se oferece para o ato da restauração é o do próprio presente da consciência observadora [...]" (BRANDI, 2004, p. 61).

Assim, a restauração nunca poderia, segundo Brandi, ser uma intervenção definitiva, pois o juízo de artisticidade varia com a passagem do tempo temporal (cronológico), podendo, em cada momento, essa intervenção ser realizada de uma forma diferente. Aqui também é óbvia a forte relação entre a contribuição de Brandi e as reflexões anteriores de Riegl, reflexões estas que Muñoz Viñas reconheceu como embriões do que ele chamou de "teoria contemporânea".

Assim, parece-nos não haver dúvida de que, embora não tenha sido literalmente explícita, a ideia de que autenticidade não é uma característica inerente dos objetos, mas uma característica atribuída no presente, está subjacente ao pensamento de Brandi.

\section{6. Últimas reflexões}

Neste artigo, vimos que o conceito de patrimônio foi ampliado para abranger toda a produção cultural que tem significado para um determinado grupo de pessoas. Essa ampliação, no entanto, não invalida os princípios de ação da prática conservadora, especialmente os sugeridos pela teoria crítica brandiana (KÜHL, 2007; CARBONARA, 2006; VIEIRA, 2004). Muñoz Viñas (2003) traz uma contribuição importante quando destaca o papel de diferentes atores envolvidos no processo de significação e o reconhecimento de um determinado bem através de um julgamento intersubjetivo e a importância de sua participação nas ações e decisões sobre conservação.

É necessário superar a visão concentrada na obra de arte, mas isso não significa invalidar a teoria brandiana (KÜHL, 2007). Vemos a contribuição de Brandi como absolutamente válida e em sintonia com o paradigma contemporâneo, fundamentado no relativismo cultural, que busca respeitar as diferenças socioculturais ao lidar com o patrimônio. Quando Brandi define restauração como um ato de cultura, portanto nunca definitivo, e condicionado à apreensão da mente humana sobre a obra de arte, tudo se torna relativo e interpretativo. Tal abordagem não poderia estar mais alinhada com o que Muñoz Viñas (2003, p. 93) defende, ao afirmar que "(...)O que pode ser tido como autêntico ou falso é o que os sujeitos pensam sobre eles [os objetos], suas ideias, suas crenças, seus juízos: não os objetos, nunca os objetos, nunca a realidade (...)".

Frente ao exposto, entendemos que essas reflexões precisam ser devidamente entendidas, contextualizadas e relativizadas para evitar a disseminação da ideia de que esses conceitos essenciais à reflexão sobre preservação do patrimônio - estão desatualizados. É primordial considerar o imaterial, os usos e significados, mas isso não significa que os conceitos de autenticidade e integridade não sejam mais úteis (VIEIRA-DE-ARAÚJO, 2014). Afinal, como afirma o próprio Muñoz Viñas (2003, p. 57), "os conservadores atuam sobre objetos tangíveis, no entanto, esses serão usados para fins intangíveis".

Por esse motivo, essas definições permanecem úteis quando se lida com o material sem desconsiderar (nem deveria) o imaterial. Reconhecer a importância da negociação entre agentes envolvidos (intersubjetividade) é uma contribuição contemporânea que pode ser perfeitamente incluída 
na formulação de julgamento crítico sobre a intervenção e pode levar a uma definição de integridade que se pretende alcançar como construção coletiva.

Portanto, a restauração deve seguir princípios gerais, vinculados a uma unidade conceitual e metodológica (algo que difere de regras estritas), às várias formas de manifestação cultural. Esses princípios devem abranger a diversidade de meios utilizados para enfrentar os problemas, de acordo com as particularidades de cada bem cultural ou de um grupo de bens, e seu percurso próprio no tempo. É um ato histórico-crítico ancorado na história e na filosofia. Esse vínculo é essencial para quem atua na preservação dos bens culturais, pois nos permite superar atitudes ditadas pelo favoritismo individual, que toda pessoa pensante possui, e por uma apreciação maior ou menor de uma determinada sociedade com relação a um determinado momento histórico. Essa abordagem permite, assim, agir sobre as manifestações culturais de outra época de acordo com uma sólida deontologia profissional, baseada em uma visão histórica.

É importante enfatizar que esse processo não é óbvio; pelo contrário, é um procedimento necessariamente multidisciplinar - justamente para minimizar o risco de atitudes individualistas, parciais e deformadoras - que exige estudos e reflexões profundas, não admitindo simplificações ou aplicações de fórmulas mecânicas, exigindo esforços interpretativos caso a caso (KÜHL, 2007, p. 208).

\section{Referências}

BRANDI, Cesare. Teoria da Restauração. São Paulo: Ateliê Editorial, 2004. Coleção Artes \& Ofícios, n. 5. $261 \mathrm{p}$.

CARBONARA, Giovanni. II restauro fra conservazione e modificazione. Principi e problemi attuali. Napoli: artstudiopaparo, 2017.

CARBONARA, Giovanni. Avvicinamento al restauro: teoria, storia, monumenti. Napoli: Liguori, 1997.

KÜHL, Beatriz Mugayar. Preservação do Patrimônio Arquitetônico da Industrialização: problemas teóricos do restauro. Cotia, SP: Ateliê Editorial, 2008. 325p.

KÜHL, Beatriz Mugayar. Restauração Hoje: Método, Projeto e Criatividade. Desígnio - Revista de História da Arquitetura e do Urbanismo, São Paulo, n.6, p. 19- 33, set. $2006 .$.

LIRA, Flaviana B. Autêntico para quem? A noção de autenticidade do patrimônio cultural na contemporaneidade. Patrimônio e Memória, Q_o Paulo, Unesp, v. 14, n. 2, p. 272-298, julhodezembro, 2018.

LIRA, Flaviana B. Da natureza complexa dos bens culturais: a indissociabilidade entre significância cultural, integridade e autenticidade. In: $\mathrm{V}$ Encontro Internacional sobre patrimônio edificado Arquimemória, Salvador, 2017. Anais do V Encontro Internacional sobre patrimônio edificado Arquimemória. Salvador: Departamento da Bahia do Instituto do Arquitetos do Brasil, 2017.

LIRA, Flaviana B. Patrimônio cultural e autenticidade: montagem de um sistema de indicadores para o monitoramento. Recife: EdUFPE, 2010.

LORETTO, Rosane Piccolo. ?q Ybcq[t cl rsp_q b_ g rcepg_bc I m N_rpgk mínio Mundial. Q_o Paulo:

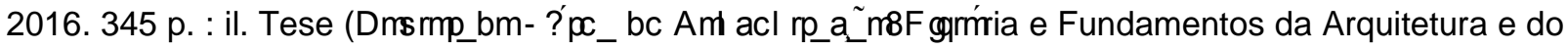
Urbanismo) - FAUUSP.

MUÑOZ VIÑAS, Salvador. Teoria contemporanea de la restauración. 1. ed. Madrid: Editorial Sintesis, 2003. 
RIEGL, Aloïs. $O$ culto moderno dos monumentos: sua essência e sua gênese. Tradução Elane Ribeiro Peixoto e Albertina Vicentine. Goiânia: Editora da UCG, 2006.

SALVO, Simona. Arranha-céu Pirelli: crônica de uma restauração. Desígnio. Revista de História da Arquitetura e Urbanismo, São Paulo, № 6, p. 69-86, Anna Blume Editora/FAU-USP, 2006.

SILVA, Paula Maciel. Conservar, uma questão de decisão: o julgamento na conservação da arquitetura moderna. Recife: Ed. Universitária da UFPE, 2012.

VIEIRA-DE-ARAÚJO, Natália Miranda. O Novo e o Antigo: Pluralidade de Posturas e a Importância do

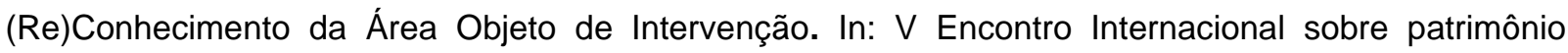
edificado - Arquimemória, Salvador, 2017. Anais do V Encontro Internacional sobre patrimônio edificado - Arquimemória. Salvador: Departamento da Bahia do Instituto do Arquitetos do Brasil, 2017.

VIEIRA-DE-ARAÙJO, Natália Miranda. Ressonâncias teóricas entre pesquisadores brasileiros e as correntes contemporâneas do restauro na Itália: e a prática?. In: V Encontro Internacional sobre patrimônio edificado - Arquimemória, Salvador, 2017. Anais do V Encontro Internacional sobre patrimônio edificado - Arquimemória. Salvador: Departamento da Bahia do Instituto do Arquitetos do Brasil, 2017.

VIEIRA-DE-ARAÚJO, Natália Miranda. Posturas Intervencionistas Contemporâneas e a Prática Brasileira Institucionalizada. III ENANPARQ arquitetura, cidade e projeto: uma construção coletiva, Campinas, 2014. In: Anais do III ENANPARQ arquitetura, cidade e projeto: uma construção coletiva. Campinas: Universidade Presbiteriana Mackenzie e Pontifícia Universidade Católica de Campinas, 2014.

VIEIRA, Natália M. Gestão de Sítios Históricos: A transformação dos valores culturais e econômicos em programas de revitalização em áreas históricas. 1. ed. Recife: Editora Universitária da UFPE, 2008. v. 300. 363p.

VIEIRA, Natália M. A Discipline in the making: classics texts on restauration revisited. City \& Time, Olinda, v.1, p. 65-69, CECl, 2004.

ZANCHETI, S, PICCOLO, Rosane. Dynamic integrity: a new concept to approach the conservation of historic urban landscape (hul). Textos para discussão - Série 1 - Gestão da conservação urbana, Olinda, CECI, V.53, 2012. 